\title{
INTERNATIONAL JOURNAL OF AUTOMOTIVE SCIENCE AND TECHNOLOGY
}

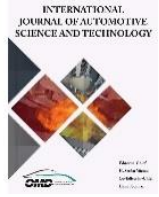

\section{Design of Fuzzy Logic Supported Car Driver Control System}

\author{
İlker Özmen ${ }^{1 *}$, Cemil Közkurt² \\ 0000-0002-6920-4429, 0000-0003-1407-9867
}

${ }^{1}$ Intelligent Transportation Systems and Technologies, Institute of Natural Sciences, Bandırma Onyedi Eylül University, Bandırma, 10200, Turkey

${ }^{2}$ Transportation Engineering, Faculty of Engineering and Natural Sciences, Bandırma Onyedi Eylül University, Bandırma, 10200, Turkey

\begin{abstract}
Being one of the most basic needs of human life, vehicles are one of the basic building blocks of transportation sector. Since automobiles are highly preferred, they cause intensity in daily traffic and need for human control increases accordingly. Approximately $88 \%$ of traffic accidents occur due to driver-related errors and approximately $1.1 \%$ of the accidents are mortal. Although there are products and studies aimed to prevent human defects technologically, such as semi-autonomous, autonomous driving systems, and driving safety components, studies to improve people's driving abilities are rare. In this study, first of all, conditions regarding proper and correct vehicle drive in traffic are examined. Then, sensor and sensor systems that can control the conditions of frequently used cars are investigated. Fuzzy logic decision making model of the sensors and subsystems used in vehicles were designed and simulated in order to develop a car driver control system (CDCS) used to provide a safety control the vehicle in traffic. As a result of the study, conceptual structure of a system that can solve decision making problem with fuzzy logic in controlling the car driver and a complex fuzzy logic model are presented. It is aimed to decrease the human defects in traffic, to teach driver to drive vehicle correctly, rapidly and economic.
\end{abstract}

Keywords: Fuzzy logic, Driving exam, Car driver, Control

\author{
Research Article \\ https://doi.org/10.30939/ijastech..902139
}

Received 24.03.2021

Revised 25.06.2021

Accepted $\quad 30.06 .2021$

* Corresponding author

İlker Özmen

ilkerozmenn@gmail.com

Address: Department of ITST, Institute of Natural Sciences, Bandırma Onyedi Eylül University, Bandırma, 10200, Turkey

Tel: +903122028653

\section{Introduction}

From a technological point of view, cars are the most important element of transformation. Cars are preferred due to their advantages such as safety, cost, and easy transportation at short distances. Due to a high preference, density in traffic flow and need for human control increase. The need of human causes negligence, accidents, and environmental pollution [1].

Driver behavior has a major impact on driving safety and fuel consumption and the monitoring and the evaluating of driver's behavior is important to improve driving safety [2]. In [3-5] driver behavior are studied. Singh [6] reported that driving errors and traffic violations are major causes in $74 \%$ of the road crashes. Rowe et.al. [7] presented a comprehensive study that one of findings is driver behavior is a major cause in the majority of the road accidents. In [8], the authors showed that recording people's vehicles online can reduce dangerous and aggressive driving behavior. In the [9] study, state-of-the-art driver behavior detection techniques classified as real time and non-real time and compared as effectiveness. Quintero et al. [10] proposed a fuzzybased driver classification system and validated it in two implementations that identify the driver for security and classify the driver into two parts, aggressive or moderate.
Recently, there has been an increase in the number of vehicles and traffic accidents in undeveloped and developing countries. Although these accidents cause loss of life and property, they negatively affect state economies [11]. Traffic rules are applied, driver controls are made in traffic, vehicle and road safety systems are developed and implemented to prevent accidents and reduce financial loss and loss of life, but unfortunately the preventions are insufficient. Considering announced Turkey Statistics Institute (TUIK) data, gravity of the situation is clearer noticed. Table 1 is given to kind of total traffic accidents across Turkey of 2019 [12].

Table 1. Road traffic accident statistics, 2019 [12]

\begin{tabular}{c|c}
\hline Total number of accidents & 1168144 \\
\hline Number of accidents involving death or injury & 174896 \\
\hline Number of accidents involving material loss only & 993248 \\
\hline
\end{tabular}

Reasons of the high number of traffic accidents involving death and injury in Turkey are high number of vehicles and drivers. The high number of drivers causes an increase in the number of driver- 
related accidents and an increase in loss of life and property is observed. Table 2 shows data of factors that lead to traffic accidents in Turkey between January and November in 2020 [12]. According to the data, drivers cause $88 \%$ of total accidents involving death and injury. It is clearly understood from the data that the good enough education of drivers or control drivers more often in traffic may be greatly prevent accidents. Traditional training approaches are costly and time consuming. Also increasing traffic controls need numerous traffic staff recruitments or electronic and smart infrastructure investment. Studies are also carried out on advanced technology products to prevent driver errors. Namely Vehicle-toAnything / Anything-to-Vehicle or V2X-X2V systems are stateof-the-art products of Intelligent Transportation Systems [13]. However, V2X-X2V systems are at stage of popularization in developed countries. Therefore, V2X-X2V systems can be a longterm solution to prevent driver errors. For a quick solution, technologies that can be used to check for driver errors and include effective driver training methods should be implemented.

Table 2. Factors causing traffic accidents involving death and injury in Turkey, 2020 [14]

\begin{tabular}{c|c}
\hline Defect Factors & Numbers of Accidents \\
\hline Driver & 156,825 \\
\hline Pedestrian & 12,489 \\
\hline Vehicle & 4,728 \\
\hline Road & 895 \\
\hline Passenger & 2,577 \\
\hline Total & 177,514 \\
\hline
\end{tabular}

Driver defects are usually caused by improper behavior reflected in driving technique due to reasons such as not obeying traffic rules, tiredness, carelessness or not reaching appropriate level of competence for driving conditions. Table 3 shows Driver defects that cause traffic accidents involving death and injury in Turkey, 2020.

In addition to effects of vehicle use on loss of life and property, its impact on environmental factors is also great. It is known that motor vehicles cause air pollution and global warming [1]. It is also possible to reduce fuel consumption with economical driving methods [15]. As a result, it is indisputable that driver control systems have a need for loss of life and property, and that motor vehicles pollute environment when used without paying attention to economic driving conditions.

In this study, modeling and simulation of a car driver control system (CDCS) using the developments in vehicle technologies in order to reduce human errors and uneconomic driving habits in traffic is discussed.

The proposed system includes functions for both training, testing and driving. CDCS will be able to support the driving exam jury to make more objective decisions. It can also be used as an exam simulator in exam preparation trainings. Moreover, it will be able to contribute to the development of the driver's abilities by controlling the driver's behavior while driving.
Table 3. Driver defects that cause traffic accidents involving death and injury in Turkey, 2020 [14]

\begin{tabular}{c|c}
\hline Driver Defects & $\begin{array}{c}\text { Number of } \\
\text { Accidents }\end{array}$ \\
\hline $\begin{array}{c}\text { Not adapting vehicle speed to the conditions required by } \\
\text { road, weather, and traffic }\end{array}$ & 61,944 \\
\hline $\begin{array}{c}\text { Failure to comply with passage priority in places where in- } \\
\text { tersections, passages and pavements are narrow }\end{array}$ & 22,237 \\
\hline $\begin{array}{c}\text { Failing to comply with lane monitoring and changing rules } \\
\text { Rear end collision }\end{array}$ & 14,702 \\
\hline Not obeying rules of changing direction (return) & 12,990 \\
\hline $\begin{array}{c}\text { Failure to comply with the general conditions governing } \\
\text { maneuvers }\end{array}$ & 11,287 \\
\hline Not stopping at red light or attendant's stop sign & 6,399 \\
\hline Entering places with no vehicles and traffic signs & 4,117 \\
\hline Failure to comply with other traffic safety rules & 3,984 \\
\hline $\begin{array}{c}\text { Not slowing down at pedestrian and school crossings, not } \\
\text { giving pedestrians right to pass }\end{array}$ & 1,487 \\
\hline Driving with alcohol & 1,870 \\
\hline Driving at excessive speed & 1,606 \\
\hline Passing through prohibited areas & 1,057 \\
\hline Parking by mistake or in prohibited places & 869 \\
\hline Other & 8,492 \\
\hline Total & 156,825 \\
\hline
\end{tabular}

\section{Design of CDCS}

\subsection{Method}

In Turkey, driver trainings are given by private driving courses affiliated with Ministry of National Education and 2 exams, written and applied, are held at the end of this training. In the trainings, subjects such as traffic and environmental rules, first aid, vehicle technique and traffic manners are explained, and it is expected that driver candidates will be successful in the written exam. Candidates who are eligible to pass the practice exam pass the driving test by giving verbal answers to questions about vehicle technique. Candidates who pass the driving inspection in accordance with traffic and environmental rules on a specified route are entitled to obtain their driver's license. The driving rules that must be followed during the test drive inspection are given in sections and items in the Lesson of on Drive Training Exam Evaluation Form (EEF) in Guide of Motor Vehicle Drivers Course, Lesson of on Drive Training Practice Exam published by Ministry of National Education [16]. Today, traffic control is carried out by the General Directorate of Security by autonomous systems or by staff in line with the data and observations made from systems such as cameras and radar at MOBESE (Mobile Electronic System Integration) centers and control points.

In this study, it is proposed a design of CDCS that can support legal control systems to deter driver and contribute to a measurable test method in the driving test and aim to improve driving abilities in cars and reduce traffic accidents caused by driver defects given in Table 3. Because CDCS offers a warning system, it provides a 
method that allows the driver to concentrate on the ride by preventing distraction.

A recent report [17] shows that driver distraction accounts for 9\% of fatal accidents. Therefore, it is predicted that future CDCS application will reduce material damage, injury and fatal accidents. However, faulty warnings due to faulty sensor signals and output values determined by experts that cannot be provided with sufficient accuracy may be the disadvantage of the system. The hardware-level implementation can only be implemented after adequate testings.
Although it is not possible to detect all of the driver behaviors with electronic systems, it seems that a significant part of the driver behaviors given in EEF [16] can be detected in automobiles with sensor, camera, navigation and LIDAR systems thanks to advanced technology. The driver behaviors aimed to be controlled using standard sensors instead of using costly equipment such as LIDAR, camera and navigation, and the logic structure to use these behaviors in control are given in Table 4 .

Table 4. Driver Behaviors, EEF abbreviations and perception methods to be used.

\begin{tabular}{|c|c|c|c|}
\hline & Driver behaviors given in EEF & $\begin{array}{c}\text { EEF } \\
\text { abbr. }\end{array}$ & $\begin{array}{l}\text { Fuzzy (F) } \\
\text { Classic (C) }\end{array}$ \\
\hline 1 & Does not wear seat belt & 3 & $\mathrm{C}$ \\
\hline 2 & Does not depress clutch (except automatic transmission vehicles) or put gear in neutral before starting vehicle. & $5 \mathrm{a}$ & $\mathrm{C}$ \\
\hline 3 & Cannot start vehicle. & $5 \mathrm{~b}$ & $\mathrm{C}$ \\
\hline 4 & Continues to keep ignition key in the starting stage, while vehicle is running. & $5 \mathrm{c}$ & F \\
\hline 5 & Does not release parking brake before moving vehicle. & $6 \mathrm{a}$ & $\mathrm{C}$ \\
\hline 6 & Does not start with correct gear, does not shift gear to D position while taking off in automatic transmission vehicles. & $6 \mathrm{~b}$ & $\mathrm{C}$ \\
\hline 7 & Does not give a signal when taking off. & $6 \mathrm{~d}$ & $\mathrm{C}$ \\
\hline 8 & While taking off, vehicle is shaking. & $6 \mathrm{e}$ & $\mathrm{F}$ \\
\hline 9 & Stops engine while taking off. & $6 \mathrm{f}$ & $\mathrm{C}$ \\
\hline 10 & Takes off quickly and uncontrolled in a way that endangers traffic. & $6 \breve{\mathrm{g}}$ & $\mathrm{F}$ \\
\hline 11 & Unable to position vehicle in correct lane after taking off. & $6 \mathrm{~h}$ & F \\
\hline 12 & Does not fully press clutch pedal when shifting gears (except for cars with automatic transmission) & $7 \mathrm{a}$ & $\mathrm{C}$ \\
\hline 13 & Cannot use accelerator pedal correctly while shifting (except for automatic transmission vehicles). & $7 \mathrm{~b}$ & $\mathrm{~F}$ \\
\hline 14 & Does not match correct sequence when shifting (except for cars with automatic transmission). & $7 \mathrm{c}$ & $\mathrm{C}$ \\
\hline 15 & When shifting, vehicle loses control (except for cars with automatic transmission). & $7 c ̧$ & $\mathrm{~F}$ \\
\hline 16 & Cannot control vehicle, swings left and right. & $8 \mathrm{~b}$ & F \\
\hline 17 & Drives vehicle through lane. & $8 \mathrm{c}$ & F \\
\hline 18 & Cannot adjust speed of the vehicle in acceleration and deceleration. & $13 \mathrm{e}$ & F \\
\hline 19 & Uses vehicle at high speed (except for automatic transmission vehicles). & $14 \mathrm{a}$ & F \\
\hline 20 & Stops and starts are sudden, does not use vehicle economically. & $14 \mathrm{c}$ & $\mathrm{F}$ \\
\hline 21 & Stops engine while taking off. & $15 \mathrm{c}$ & $\mathrm{C}$ \\
\hline 22 & Makes vehicle stop. & $16 \mathrm{~d}$ & $\mathrm{C}$ \\
\hline 23 & Does not give a signal when taking off. & $16 \mathrm{~g}$ & $\mathrm{C}$ \\
\hline 24 & Cannot brake and stop vehicle suddenly (when traveling at $30 \mathrm{~km} / \mathrm{h}$ ). & $17 \mathrm{a}$ & $\mathrm{C}$ \\
\hline 25 & Stops vehicle when it brakes suddenly. & $17 \mathrm{~b}$ & $\mathrm{C}$ \\
\hline 26 & Does not give a signal before taking off. & $17 c ̧$ & $\mathrm{C}$ \\
\hline 27 & Stops engine while taking off. & $17 \mathrm{e}$ & $\mathrm{C}$ \\
\hline 28 & Does not signal before stopping or taking off in right lane. & $18 \mathrm{~b}$ & $\mathrm{C}$ \\
\hline 29 & When moving the vehicle, moves back more than $50 \mathrm{~cm}$. & $18 \mathrm{~d}$ & $\mathrm{C}$ \\
\hline 30 & Stops engine while taking off. & $18 \mathrm{e}$ & $\mathrm{C}$ \\
\hline 31 & Stops engine while taking off. & $19 \mathrm{~d}$ & $\mathrm{C}$ \\
\hline 32 & Does not give signals when leaving parking area. & $19 \mathrm{~g}$ & $\mathrm{C}$ \\
\hline 33 & Does not give a signal when approaching to right when pausing or parking. & $20 \mathrm{c}$ & $\mathrm{C}$ \\
\hline 34 & Does not stabilize vehicle with parking brake before leaving the vehicle. & $20 \mathrm{f}$ & $\mathrm{C}$ \\
\hline 35 & Does not turn off engine before leaving vehicle. & $20 \mathrm{~g}$ & $\mathrm{C}$ \\
\hline 36 & Does not shift gear to P position before stopping vehicle during parking in vehicles with automatic transmission. & $20 \breve{g}$ & $\mathrm{C}$ \\
\hline
\end{tabular}

The 36 behaviors given in Table 4 are behaviors that can occur based on a scenario or during each ride. These behaviors can be controlled with Classic Logic or Fuzzy Logic. Decision making with fuzzy logic was preferred because decision making in 11 behaviors with output values in a continuous range may vary from person to person. Classical logic decision-making is used in 25 behaviors with discrete or true-false values.

Since sensor systems in cars have different properties and structures, it does not seem that creating a system that controls all of the driver behavior is a very comprehensive project. However, it is 
also possible to perform many driving inspections when sensor and sensor systems, which are standard in vehicles, are used. Matching use of the sensors required for control system in the driver behav- iors to be inspected is given in Table 5. Accordingly, in a simulation model, sensor information is determined as input and behavior of the controlled driver is determined as output.

Table 5. Matching necessary sensors for CDCS with EEF behaviors

\begin{tabular}{|c|c|c|c|c|c|c|c|c|c|c|c|c|c|c|c|c|}
\hline & $\pi$ & $\tilde{\omega}$ & $\tilde{n}$ & जे & $n$ & is & $\hat{n}$ & $\infty$ & हे & $\stackrel{8}{n}$ & $\bar{n}$ & $\underset{\infty}{\pi}$ & $\stackrel{*}{\frac{*}{\omega}}$ & $\frac{\pi}{\infty}$ & $\stackrel{2}{\infty}$ & $\frac{\bullet}{n}$ \\
\hline & 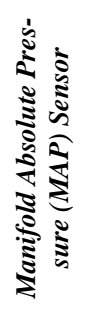 & 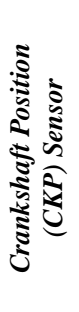 & 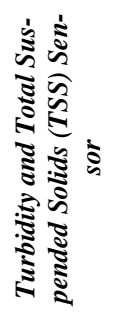 & 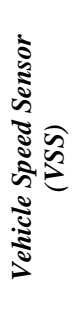 & 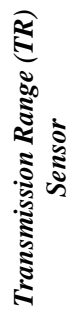 & 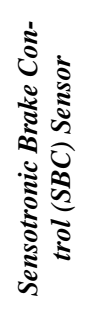 & 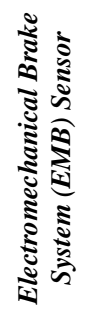 & 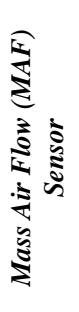 & 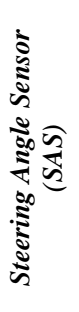 & 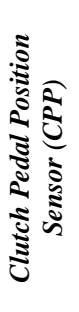 & 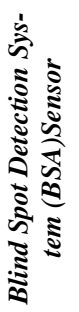 & 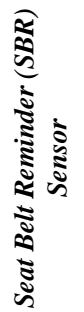 & 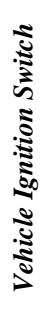 & 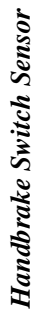 & 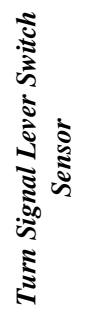 & 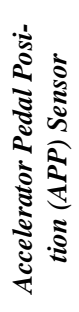 \\
\hline $3-C$ & & & & & & & & & & & & & & & & \\
\hline $5 a-C$ & & & & & & & & & & & & & & & & \\
\hline $5 b-C$ & & & & & & & & & & & & & & & & \\
\hline $5 c-F$ & & & & & & & & & & & & & & & & \\
\hline $6 a-C$ & & & & & & & & & & & & & & & & \\
\hline $6 b-C$ & & & & & & & & & & & & & & & & \\
\hline $6 d-C$ & & & & & & & & & & & & & & & & \\
\hline $6 e-F$ & & & & & & & & & & & & & & & & \\
\hline $6 f-C$ & & & & & & & & & & & & & & & & \\
\hline $6 \breve{g}-F$ & & & & & & & & & & & & & & & & \\
\hline $6 h-F$ & & & & & & & & & & & & & & & & \\
\hline $7 a-C$ & & & & & & & & & & & & & & & & \\
\hline $7 b-F$ & & & & & & & & & & & & & & & & \\
\hline $7 c-C$ & & & & & & & & & & & & & & & & \\
\hline $7 c ̧-F$ & & & & & & & & & & & & & & & & \\
\hline $8 b-F$ & & & & & & & & & & & & & & & & \\
\hline $8 c-F$ & & & & & & & & & & & & & & & & \\
\hline $13 e-F$ & & & & & & & & & & & & & & & & \\
\hline $14 a-F$ & & & & & & & & & & & & & & & & \\
\hline $14 c-F$ & & & & & & & & & & & & & & & & \\
\hline $15 c-C$ & & & & & & & & & & & & & & & & \\
\hline $16 d-C$ & & & & & & & & & & & & & & & & \\
\hline $16 \mathrm{~g}-\mathrm{C}$ & & & & & & & & & & & & & & & & \\
\hline $17 a-C$ & & & & & & & & & & & & & & & & \\
\hline $17 b-C$ & & & & & & & & & & & & & & & & \\
\hline $17 c ̧-C$ & & & & & & & & & & & & & & & & \\
\hline $17 e-C$ & & & & & & & & & & & & & & & & \\
\hline $18 b-C$ & & & & & & & & & & & & & & & & \\
\hline $18 d-C$ & & & & & & & & & & & & & & & & \\
\hline $18 e-C$ & & & & & & & & & & & & & & & & \\
\hline $19 d-C$ & & & & & & & & & & & & & & & & \\
\hline $19 g-C$ & & & & & & & & & & & & & & & & \\
\hline $20 c-C$ & & & & & & & & & & & & & & & & \\
\hline $20 f-C$ & & & & & & & & & & & & & & & & \\
\hline $20 \mathrm{~g}-\mathrm{C}$ & & & & & & & & & & & & & & & & \\
\hline $20 \breve{g}-C$ & & & & & & & & & & & & & & & & \\
\hline
\end{tabular}

: Sensors with logical output (Suitable for Classic Logic), *S13 sensor is assumed analogue via on/off time cycle of output.

\subsection{Fuzzy Logic}

Modeling with fuzzy logic was first proposed by Lotfi Ali-asker Zadeh [18] and since then it has been used in many areas such as information systems, control systems and optimization. Especially
: Sensors with analogue or wide scale output (Suitable for Fuzzy Logic)

common use of fuzzy logic in control systems was provided by Mamdani [19]. It is also used in control designs in automotive industry today [20]. Mamdani method was used as a fuzzy logic in- 
ference mechanism in CDCS. Fuzzy result area is obtained by examining membership functions of the rules in Mamdani fuzzy inference structure with trimming (min-max) method as in Fig. 1. Areas are aggregated in Fig. 2. Equation associated with membership functions of the Mamdani fuzzy inference is given in Eq.1 [21].

$$
Z_{i}=\left(\sigma_{x i}(\mathrm{a}) \cap \sigma_{y i}(\mathrm{~b})\right) \cap \sigma_{z i}(\mathrm{c})
$$

In the equation, $\sigma_{x}$ and $\sigma_{y}$ indicate input parameters of the membership functions, and $\sigma_{z}$ indicates output parameters. Mamdani fuzzy inference structure is given in Fig. 1, with membership levels of membership functions being $\lambda$.

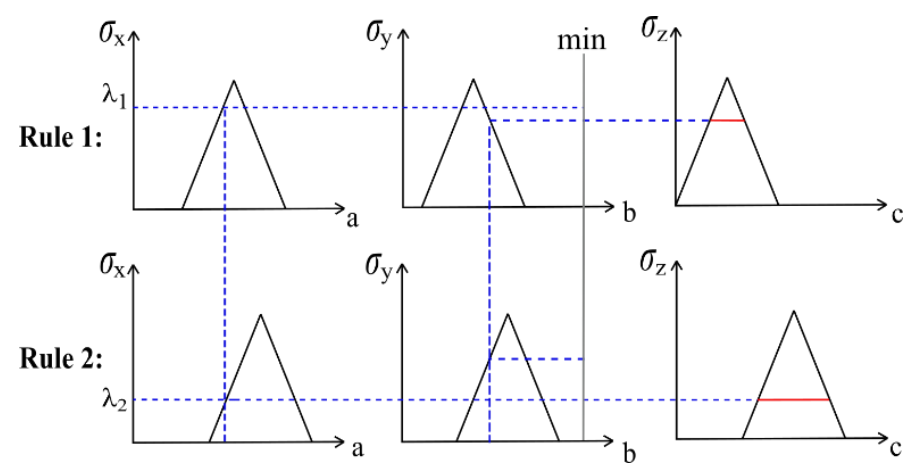

Fig.1. Mamdani Fuzzy Inference Structure

If there are $m$ rules in inference structure, total inference area is obtained by Eq 2. Fuzzy inference result combination graph is obtained in a fuzzy system with two-rule as in Fig 2.

$$
Z_{\text {out }}=\bigcup_{i=1}^{m}(Z i)
$$

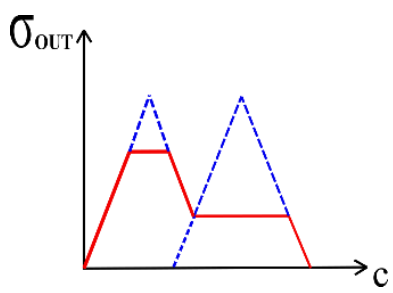

Fig. 2. Mamdani result aggregation

Defuzzification is performed via fuzzy result graph. Center of area (COA) method is applied while performing defuzzification action. This is because COA method has a lower margin of error and result values are more converged. There are two equations for this method. If the fuzzy inference result merge graph consists of two separate areas, Eq. 3 is used.

$C_{C O A}=\frac{\sum_{i=K}^{L}\left(\lambda_{i}\right)\left(Z_{i}\right)}{\sum_{i=K}^{L}\left(\lambda_{i}\right)}$

If the fuzzy inference result combination graph is obtained by intersection of the areas of the two graphs, Eq. 4 is used.

$$
C_{C O A}=\frac{\int_{C_{K}}^{C_{L}}\left(\boldsymbol{\lambda}_{\boldsymbol{i}}\right)\left(\boldsymbol{Z}_{\boldsymbol{i}}\right)(\boldsymbol{Z} d \boldsymbol{Z})}{\int_{C_{K}}^{C_{L}}\left(\boldsymbol{\lambda}_{\boldsymbol{i}}\right)(\boldsymbol{Z} d \boldsymbol{Z})}
$$

The closest value which shown a sample in Fig. 3 is obtained with COA defuzzification method.

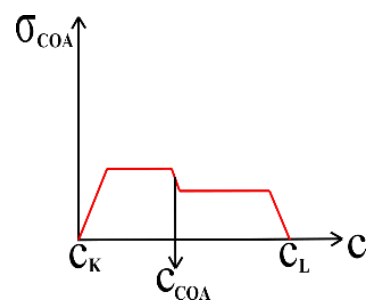

Fig 3. Mamdani center of area defuzzification

2.3 Fuzzy Problem Rules of CDCS: In the proposed CDCS, driver behaviors are detected by sensors, and the detected data is transmitted to decision-making sub-system and the driver behavior evaluation result is obtained by using classical logic or fuzzy logic. According to the evaluation, car driver is alerted or guided by output units such as an interface, sound or vibration. Block diagram of the CDCS with fuzzy sub-system, which includes the car driver assisted via this method, is given in Fig. 4.

The full model of CDCS can be completed as a result of the classical logic evaluation of the sensor data with $0 / 1$ output, but this is a simpler engineering solution. The fuzzy logic model, on the other hand, has been emphasized more in the study, since solution of the problem involves a complex process in terms of its originality. That's why Fig. 4 shows a conceptual design of a part of the CDCS including fis5c however full fuzzy part of the system's simulation is represented in study.

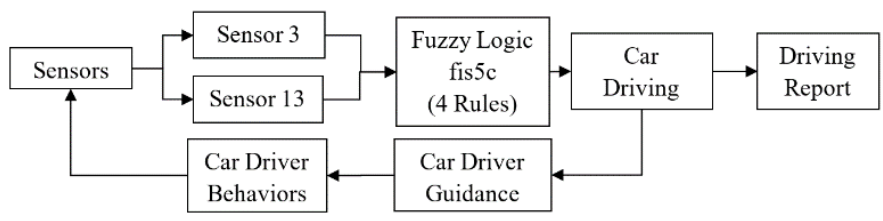

Fig. 4. Block Diagram of CDCS including system fis5c: 2 inputs, 1 output, 4 rules

Reason for using fuzzy logic in CDCS is that there are some ambiguous decision-making intervals. For example, separating a hard take off with an exact value may be far from human decisionmaking. For this reason, fuzzy logic theory can be used in cases where classical logic is insufficient. The data belonging to a criterion determined according to the fuzzy logic structure can also qualify a different value belonging to another criterion. Fuzzy logic differs from classical logic structure due to its flexible classification structure [22]. All fuzzy logic rules of CDCS are given in Table 6 . 
Table 6. Fuzzy rules of CDCS with all used sensors

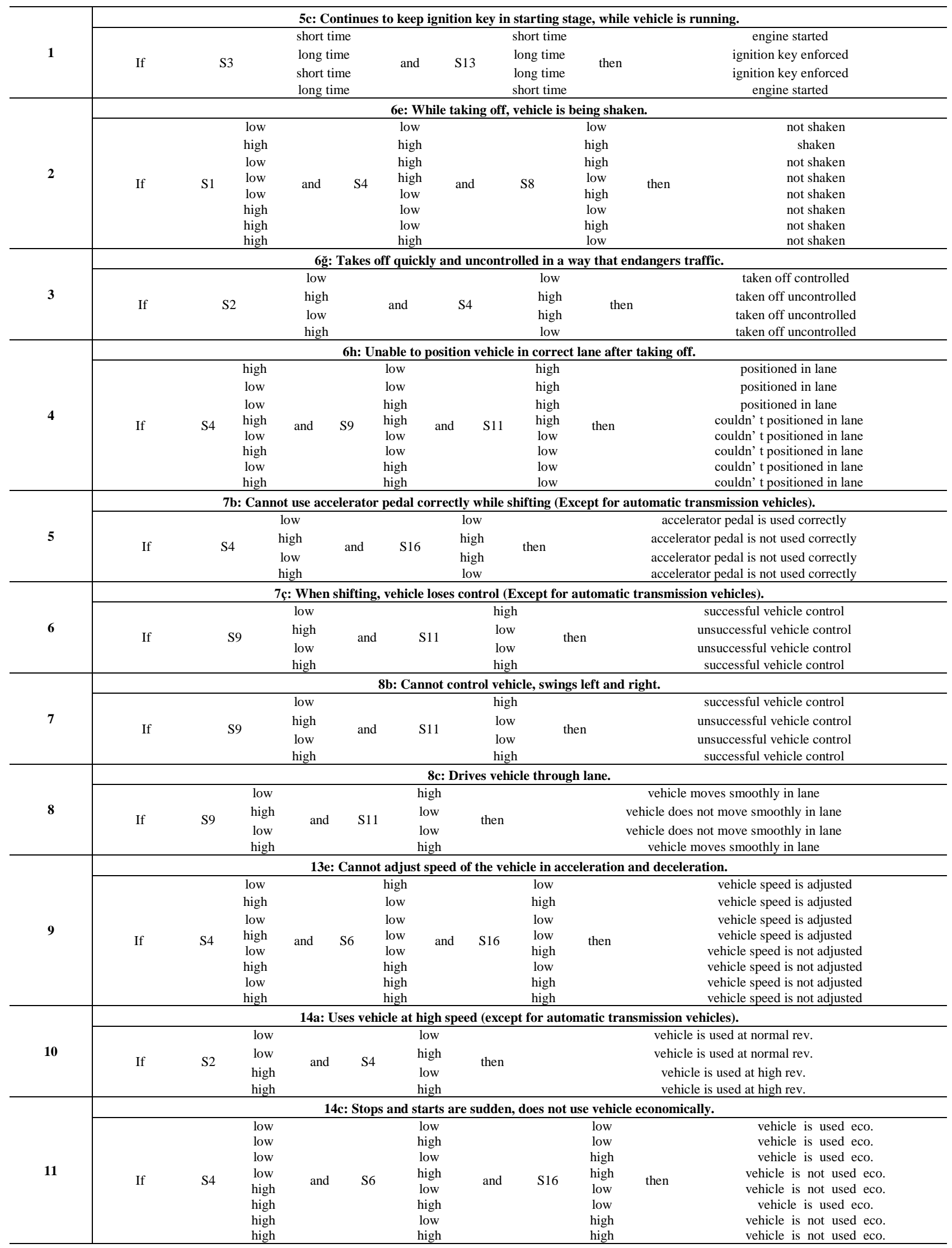


In the classical logic structure, a data either belongs to the specified criterion or not. In other words, it consists of logical zeros and ones. In fuzzy logic, membership level increases as value of the membership function approaches 1 , among infinite values between 0 and 1 , and the membership level decreases as it approaches 0 . In fuzzy logic, due to flexible structure of the functions and partial membership of data, each data has a degree of membership over the specified functions [23].

The fuzzy logic method applied in the study was implemented by coding functions of the Fuzzy Logic Toolbox under MATLAB software developed by the MathWorks company. Although there is an interactive graphical user interface of the same toolbox, the coding approach has been preferred to achieve a more effective flexibility and graphic resolution.

\section{Simulation Model and Results}

\subsection{Fuzzy Logic Simulation Model:}

The fuzzy logic method applied in the designed CDCS is taken from necessary inputs from sensors and determined as variable values between 0 and 1 . In order to examine a determined rule with fuzzy logic, the data received from the sensors must reach a certain result in all possible conditions. $5 \mathrm{c}$ is considered as an example for model of the rules to be controlled with fuzzy logic. There are 2 sensor inputs, 4 rules and 1 result data to set up the model for $5 \mathrm{c}$. Decision paragraph of the rules of $5 \mathrm{c}$ is given below.

- If starter motor works for a long time, starter is forced, if the starter motor sends a signal for a short time, engine has run. When a short-term or long-term signal is received from turbine shaft speed sensor, it is understood that engine is running. If signal from the starter motor is higher than the specified value since engine starts, the starter motor will be forced and this situation will be notified to car driver as a warning.

Fuzzy logic model of $5 c$ is given in Fig.5.

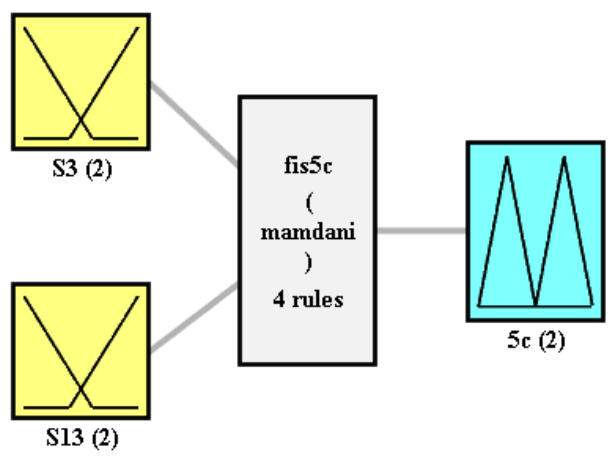

System fis 5 c: 2 inputs, 1 outputs, 4 rules

Fig. 5. Fuzzy logic model of 5c
Membership function graphs of $5 \mathrm{c}$ input parameters are given in Fig. 6 and Fig 7.

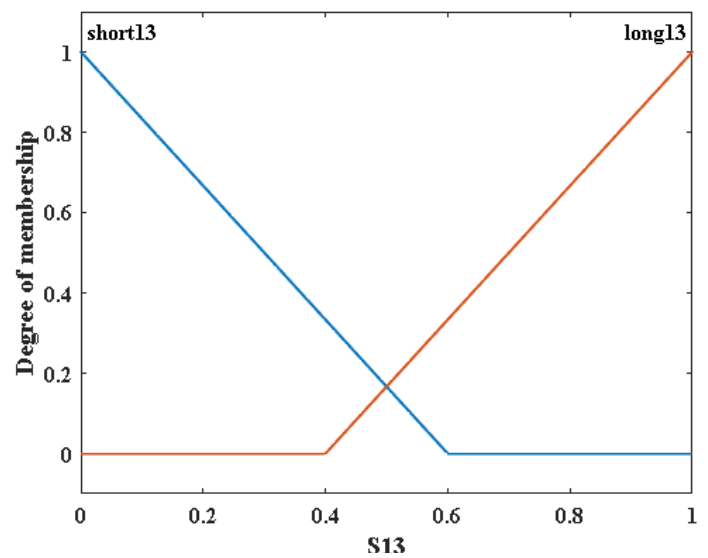

Fig. 6. Membership function graph of input S13 of 5c

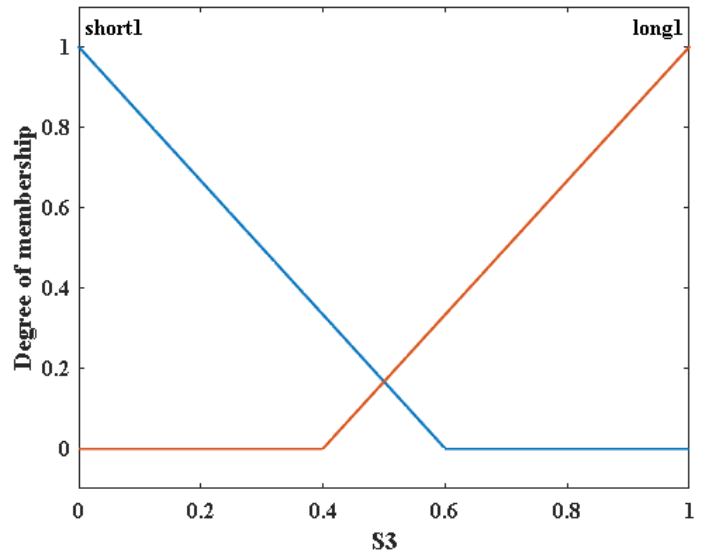

Fig. 7. Membership function graph of input S3 of 5c

Membership function graph of output $5 \mathrm{c}$ is given in Fig. 8.

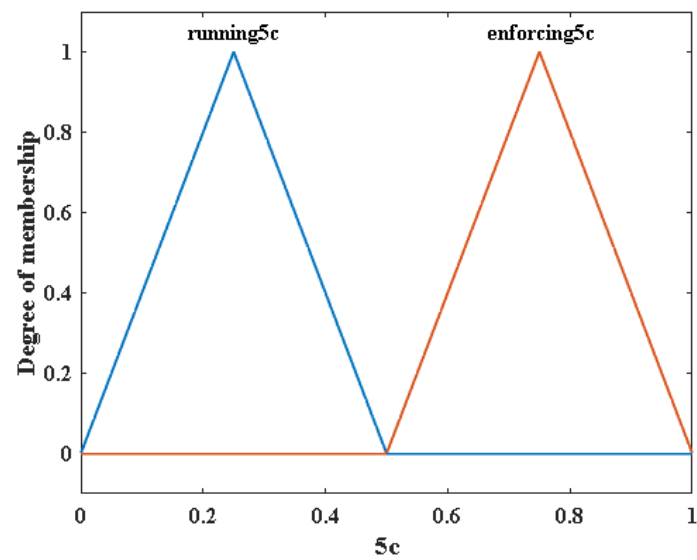

Fig. 8. Membership function graph of output $5 \mathrm{c}$ 


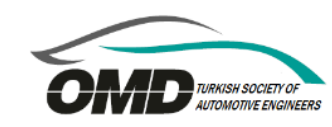

\subsection{Results of Fuzzy Logic Simulation Model:}

Result graph obtained according to fuzzy logic conditions of $5 \mathrm{c}$ inputs S3 and S13 sensors is given in Fig. 9.

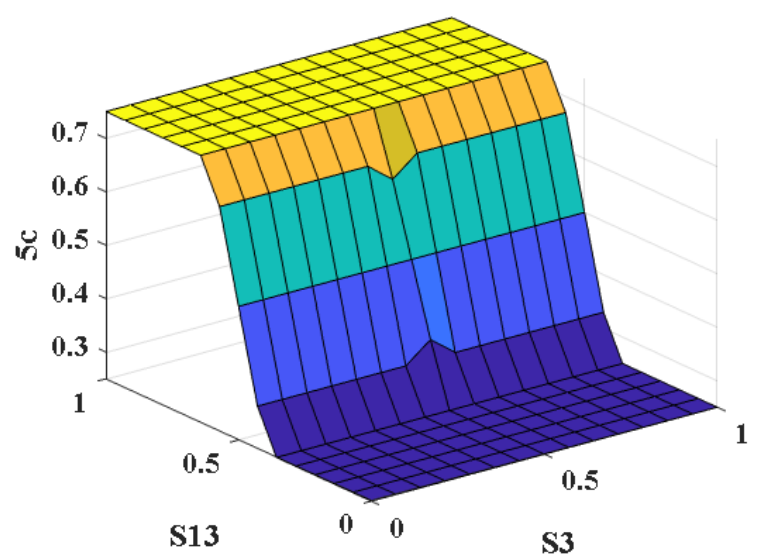

Fig. 9. The effect of S3 and S13 sensors on result of the $5 \mathrm{c}$

Except for 5c, which will be controlled with fuzzy logic, all other evaluations have been created in the order given above.

The rules of fuzzy logic theory used in CDCS are created according to the conditions given in Table 6 of the input values taken from the sensors. In order to obtain result graphics, fuzzy decision system is input from sensors of the determined rule chain. Sensor values are normalized between 0 and 1 and can be different for each rule. However, to indicate that the output values will differ according to established rules, all sensor values were applied as 0.75 in simulation experiment. This value will enable the "high" graph, that is, fuzzy logic to determine value input from the sensor as a high value in membership functions. After the fuzzy decision made according to the rules given in Table 6, a result value is obtained. The input and output values given in Table 7 for all items are examined and it is seen that the results obtained are compatible with the output graphs given in Fig.10.

Results of constant inputs of value 0.75 are given in Table 7 . These results form the fuzzy part of CDCS and the whole driving report given in Fig.4 can be combined with the decision results of the classic part.
Table 7. Results of fuzzy model of CDCS

\begin{tabular}{|c|c|c|c|c|c|}
\hline Rules & Inputs & $\begin{array}{l}\text { Sensor } \\
\text { Value }\end{array}$ & Function & $\begin{array}{c}\text { Output } \\
\text { Value }\end{array}$ & $\begin{array}{l}\text { Output } \\
\text { Function }\end{array}$ \\
\hline \multirow{2}{*}{$5 c$} & $\mathrm{~S} 3$ & 0.75 & long time & \multirow{2}{*}{0.75} & \multirow{2}{*}{$\begin{array}{l}\text { ignition key } \\
\text { enforced }\end{array}$} \\
\hline & $\mathrm{S} 13$ & 0.75 & long time & & \\
\hline \multirow{3}{*}{$6 \mathrm{e}$} & $\mathrm{S} 1$ & 0.75 & high & \multirow{3}{*}{0.75} & \multirow{3}{*}{ shaken } \\
\hline & $\mathrm{S} 4$ & 0.75 & high & & \\
\hline & S8 & 0.75 & high & & \\
\hline \multirow{2}{*}{$6 \breve{g}$} & $\mathrm{~S} 2$ & 0.75 & high & \multirow{2}{*}{0.75} & \multirow{2}{*}{$\begin{array}{c}\text { taken off } \\
\text { uncontrolled }\end{array}$} \\
\hline & $\mathrm{S} 4$ & 0.75 & high & & \\
\hline \multirow{3}{*}{$6 h$} & $\mathrm{~S} 4$ & 0.75 & high & & \multirow{3}{*}{$\begin{array}{l}\text { couldn't } \\
\text { position } \\
\text { in lane }\end{array}$} \\
\hline & S9 & 0.75 & high & 0.75 & \\
\hline & S11 & 0.75 & high & & \\
\hline \multirow{2}{*}{$7 b$} & $\mathrm{~S} 4$ & 0.75 & high & \multirow{2}{*}{0.75} & \multirow{2}{*}{$\begin{array}{l}\text { acc. pedal is } \\
\text { not used } \\
\text { correctly }\end{array}$} \\
\hline & $\mathrm{S} 16$ & 0.75 & high & & \\
\hline \multirow{2}{*}{$7 c ̧$} & S9 & 0.75 & high & \multirow{2}{*}{0.25} & \multirow{2}{*}{$\begin{array}{l}\text { successful } \\
\text { vehicle control }\end{array}$} \\
\hline & $\mathrm{S} 11$ & 0.75 & high & & \\
\hline \multirow{2}{*}{$8 b$} & S9 & 0.75 & high & \multirow{2}{*}{0.25} & \multirow{2}{*}{$\begin{array}{c}\text { successful } \\
\text { vehicle control }\end{array}$} \\
\hline & $\mathrm{S} 11$ & 0.75 & high & & \\
\hline \multirow{2}{*}{$8 c$} & S9 & 0.75 & high & \multirow{2}{*}{0.25} & \multirow{2}{*}{$\begin{array}{c}\text { vehicle moves } \\
\text { smoothly in } \\
\text { lane }\end{array}$} \\
\hline & S11 & 0.75 & high & & \\
\hline \multirow{3}{*}{$13 \mathrm{e}$} & $\mathrm{S} 4$ & 0.75 & high & \multirow{3}{*}{0.75} & \multirow{3}{*}{$\begin{array}{l}\text { vehicle speed } \\
\text { is not adjusted }\end{array}$} \\
\hline & S6 & 0.75 & high & & \\
\hline & S16 & 0.75 & high & & \\
\hline \multirow{2}{*}{$14 \mathrm{a}$} & $\mathrm{S} 2$ & 0.75 & high & \multirow{2}{*}{0.75} & \multirow{2}{*}{$\begin{array}{c}\text { vehicle is used } \\
\text { at high rev. }\end{array}$} \\
\hline & $\mathrm{S} 4$ & 0.75 & high & & \\
\hline \multirow{3}{*}{$14 \mathrm{c}$} & $\mathrm{S} 4$ & 0.75 & high & & \multirow{3}{*}{$\begin{array}{c}\text { vehicle is not } \\
\text { used } \\
\text { economically }\end{array}$} \\
\hline & S6 & 0.75 & high & 0.75 & \\
\hline & S16 & 0.75 & high & & \\
\hline
\end{tabular}

For example, when the data given in Table 7 for item $5 \mathrm{c}$ is examined, it is determined that sensor input values are 0.75 , membership functions are determined as long time, and when the second rule is examined from Table 6 , the result should be "ignition key enforced" and its value is determined. We see that it should be 0.75 .

Results graphs obtained by using the conditions given in the Method section are given in Fig. 10. The levels of the decision outputs produced by the fuzzy model are seen against sensor input values. Since rules generally have two inputs, sensor values are seen on the horizontal axes of the graphs and decision result value of the fuzzy model on the vertical axis. In the rules with three inputs, it is seen that a multi-stage exit surface is formed. 


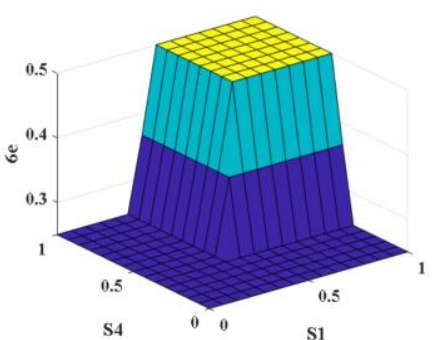

a)

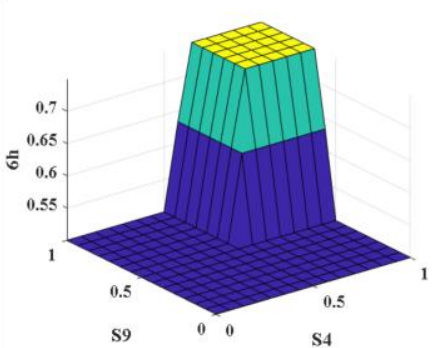

c)

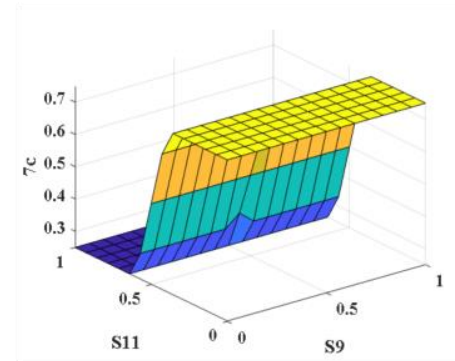

e)

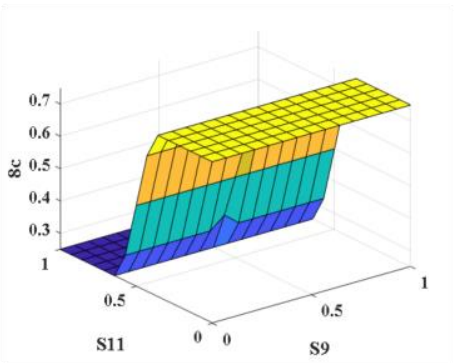

g)

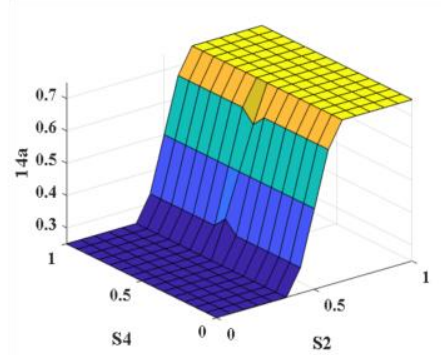

i)

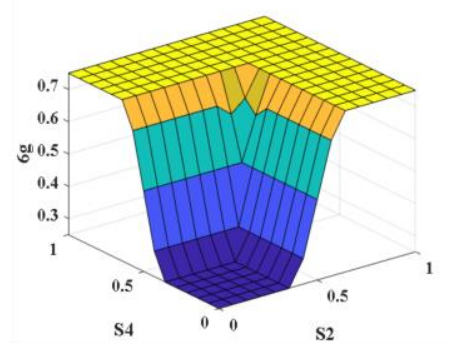

b)

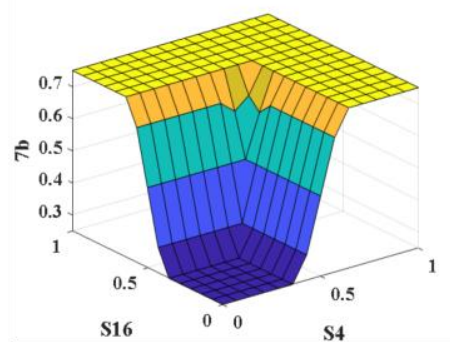

d)

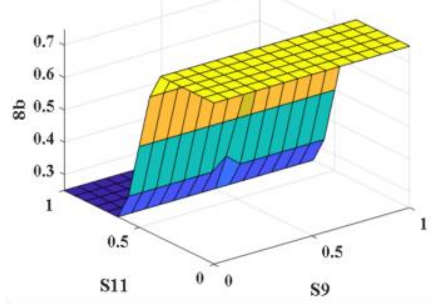

f)

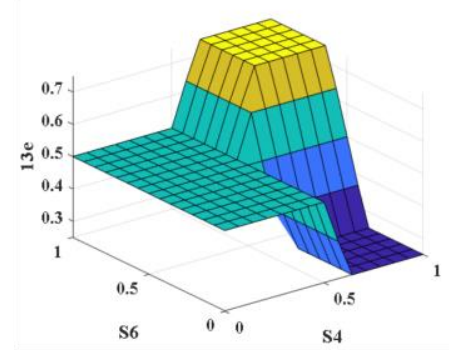

h)

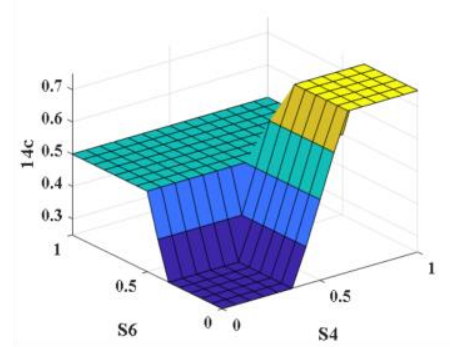

j)

Fig. 10. Fuzzy logic result graphs of CDCS sensors vs. evaluations a)6e vs S1, S4 b)6 $\breve{g}$ vs S2, S4 c)6h vs S4, S9 d)7b vs S4, S16 e)7ç vs S9, S11 f) 8 b vs S9, S11 g)8c vs S9, S11 h)13e vs S4, S6 i)14a vs S2, S4 j) 14c vs S4, S6 


\section{Conclusion}

In this study, a car drive control system (CDCS) design is proposed and the fuzzy logic section is modeled using MATLAB Fuzzy Logic Toolbox codes. Simulation approach was used in the study and no experiments were made on any hardware. The evaluation of the data obtained from the sensors as a result of the experiments can be planned under the supervision of an expert. Since this is an experimental project in itself, a design was made with hypothetical input and output values in the study. When the hardware system is created, expert opinions can be easily integrated into the system as a constant value.

In CDCS, data received from appropriate sensors of the vehicle were created with fuzzy logic according to the conditions suitable for the evaluations in EEF. Graphs of the effects of the input sensors on the outputs are given. As a result, the conceptual structure of a system that can solve decision making with fuzzy logic in controlling and assisting the driver and a complex fuzzy logic model are presented. In future studies, it will be possible to work on a hardware design and production of the system. Although the results of the study are for manual transmission vehicles, the system can be adapted to automatic transmission, diesel or gasoline vehicle types by making arrangements on the rules. In addition, the system can be adapted for electric and semi-autonomous vehicles and these adaptations will be simpler than the first design. The full model of CDCS can be completed as a result of the classical logic evaluation of the sensor data with $0 / 1$ output, but this is a simpler engineering solution. The fuzzy logic model, on the other hand, has been emphasized more in the study, since the solution of the problem involves a complex process in terms of its originality. An interactive driving training system is realized by creating a driver warning and evaluation system with the implementation of the modeling in a hardware. However, it would be possible for driver to test himself before the driving test with the CDCS. It is anticipated that driving practice exams with CDCS-equipped vehicles will be more objective. Also, the use of CDCS in traffic after training is predicted to prevent memorizing driving. Although the use of non-autonomous vehicles will decrease in the future, it is possible that driving is a sport in private areas, just as horse riding is a sport. In the future, CDCS will pave the way for systems that will enable people to learn to drive faster and on their own.

\section{Acknowledgment}

This study is a part of the thesis project managed in Intelligent Transformation Systems and Technologies Department, Institute of Natural Sciences, Bandırma Onyedi Eylül University.

\section{Conflict of Interest Statement}

The authors of this manuscript certify that they have no affiliations with or involvement in any organization or entity with any financial interest, or non-financial interest in the subject matter or materials discussed in this manuscript.

\section{CRediT Author Statement}

İlker Özmen: Conceptualization, Data Curation, Formal Analysis, Software, Visualization, Writing-original draft

Cemil Közkurt: Conceptualization, Methodology, Supervision, Validation, Visualization, Writing - Review \& Editing.

\section{References}

[1] Özen A, Onural A. Egzoz emisyon sistemlerinin neden olduğu çevre kirliliği. 7. Otomotiv ve Yan Sanayi Sempozyumu. Bursa: TMMOB Makine Mühendisleri Odası. 2001; 107-112.

[2] Eftekhari HR, Ghatee MA. Similarity-based neuro-fuzzy modeling for driving behavior recognition applying fusion of smartphone sensors. Journal of Intelligent Transportation Systems 2019; 23(1): 7283.

[3] Bejani MM, Ghatee MA. Context aware system for driving style evaluation by an ensemble learning on smartphone sensors data. Transportation Research Part C: Emerging Technologies. 2018; 89: 303-320.

[4] Castignani G, Derrmann T, Frank R, Engel T. Driver behavior profiling using smartphones: A low-cost platform for driver monitoring. IEEE Intelligent Transportation Systems Magazine. 2015; 7(1): 91102.

[5] Chen Z, Yu J, Zhu Y, Chen Y, Li MD. 3: Abnormal driving behaviors detection and identification using smartphone sensors. In 2015 12th Annual IEEE International Conference on Sensing, Communication, and Networking (SECON) IEEE. 2015; 524-532.

[6] Singh S. Critical reasons for crashes investigated in the National Motor Vehicle Crash Causation Survey. (Traffic Safety Facts Crash Stats. Report No. DOT HS 812 115). Washington, DC: National Highway Traffic Safety Administration. 2015.

[7] Rowe R, Roman GD, McKenna FP, Barker E, Poulter D. Measuring errors and violations on the road: A bifactor modeling approach to the Driver Behavior Questionnaire. Accident Analysis \& Prevention. 2015; 74: 118-125.

[8] Hickman JS, Scott Geller E. Self-management to increase safe driving among short-haul truck drivers. Journal of Organizational Behavior Management. 2005; 23(4): 1.

[9] Chhabra R, Verma S, Krishna CR. A survey on driver behavior detection techniques for intelligent transportation systems. In 2017 7th International Conference on Cloud Computing, Data Science \& Engineering-Confluence IEEE. 2017; 36-41.

[10]CG Quintero M, JO López, AC Cuervo Pinilla. Driver behavior classification model based on an intelligent driving diagnosis system. 2012 15th International IEEE Conference on Intelligent Transportation Systems. 2012; 894-899.

[11]Karaoğlu R. Motorlu Kara Taşıtlarında Meydana Gelen Maddi Hasarlı Trafik Kazalarının Ülke Ekonomisine Etkisi. Bursa: Bursa Uludağ Üniversitesi, Master's Thesis. 2019.

[12]Temel İstatistiksel Tablolar. Türkiye İstatistik Kurumu: https://data.tuik.gov.tr/Bulten/Index?p=Road-Traffic-Accident-Statistics-2019-33628 adresinden alındı. 2018.

[13]Pearre, Nathaniel S, Ribberink, Hajo. Review of research on V2X technologies, strategies, and operations. Renewable and Sustainable Energy Reviews. 2019; 105: 61-70. 
[14]http://www.trafik.gov.tr/kurumlar/trafik.gov.tr/04-Istatistik/Aylik/aralilk20.pdf. 2020.

[15]Chaim M, Shmerling VE. A Model for Vehicle Fuel Consumption Estimation at Urban Operating Conditions. International Journal of Mechanics 2013; 7: 18-23.

[16] Motorlu Taşıt Sürücüleri Kursu Direksiyon Eğitimi Dersi Uygulama Sınavı Kılavuzu, Özel Öğretim Kurumları Genel Müdürlüğü, T.C. Milli Eğitim Bakanlığı, 2018; 77-78.

[17]National Center for Statistics and Analysis. Distracted driving 2019 (Research Note. Report No. DOT HS 813 111). National Highway Traffic Safety Administration. 2021.

[18]Zadeh LA. Fuzzy Sets. Inf. Control 1965; 8: 338-353.

[19]Mamdani EH, Assilina S. An Experiment in Linguistic Synthesis with a Fuzzy Logic Controller. Int. J. Man-Mach. Stud. 1975; 7: 113.

[20]Yatak MÖ, Şahin F. Ride Comfort-Road Holding Trade-off Improvement of Full Vehicle Active Suspension System by Interval Type-2 Fuzzy Control. Engineering Science and Technology, an International Journal.2021; 24(1): 259-270.

[21]Jang J-SR, Sun C-T., Mizutani E. Neuro-Fuzzy and Soft Computing: A Computational Approach to Learning and Machine Intelligence, New Jersey, USA, Prentice Hall, 1997.

[22]Tiryaki AE, Kazan R. Bulaşık Makinesinin Bulanık Mantık ile Modellenmesi. Mühendis ve Makina. 2007; 3-8.

[23]Kişi Ö, Karahan ME, Şen Z. (2010). Nehirlerdeki askı maddesi miktarının bulanık mantık ile modellenmesi. İTÜ Dergisi, 2010; 2(3): 43-54. 